\title{
La reflexividad sobre los procesos de enseñanza y aprendizaje de la investigación en ciencias sociales ${ }^{1}$
}

\author{
Jefferson Jaramillo Marín² \\ Facultad Latinoamericana de Ciencias Sociales, México, D.F.
}

Recibido: 20 de abril de 2010 - Aprobado: 19 de mayo de 2010

\section{Resumen}

El ensayo discute sobre la "reflexividad" en el marco de los procesos de enseñanza-aprendizaje de la investigación en ciencias sociales. Se señala la importancia de este ejercicio en la teoría social contemporánea y su conexión con el oficio y práctica del investigador social. A partir de un ejercicio autorreflexivo, surgido desde el oficio de la docencia universitaria en un programa de sociología, se plantean específicamente algunas implicaciones y retos de la investigación social.

Palabras clave: reflexividad, ciencias sociales, procesos de enseñanzaaprendizaje, investigación.

1 El presente es un artículo de reflexión, fruto de las investigaciones del autor para optar al título de Doctor en Investigación en Ciencias Sociales de la FLACSO.

2 Sociólogo y Magíster en Filosofía Política de la Universidad del Valle, Cali, Colombia. Profesor asistente del departamento de Sociología de la Facultad de Ciencias Sociales de la Pontificia Universidad Javeriana, Bogotá, Colombia. Candidato a Doctor en Investigación en Ciencias Sociales de la FLACSO-México, D. F. Becario del CONACYT, México. Correo electrónico: jefferson.jaramillo@javeriana.edu.co; jefferson. jaramillo@flacso.edu.mx. 


\section{Reflexivity on teaching learning research processes in social sciences}

\section{A bstract}

This essay discusses the "reflexivity" in the teaching learning research processes framework in social sciences. The importance of this practice is pointed out in the social contemporary theory and its connection with the social researcher's profession and practice. Starting from a self-reflective exercise, which emerges from the university teaching profession in a Sociology Program, some implications and challenges of social research are specifically posed.

Key words: reflexivity, social sciences, teaching-learning processes, research. 


\section{La reflexivité sur les processus d'enseignement- apprentissage de la recherche en sciences sociales}

\section{Résumé}

L'essai discute de la "réflexivité" dans le cadre des processus d'enseignementapprentissage de la recherche en sciences sociales. On signale l'importance de cet exercice dans la théorie sociale contemporaine et sa connexion avec le travail et la pratique du chercheur en sciences sociales. A partir d'un exercice auto-réflexif, surgi du métier de l'enseignement universitaire dans un programme de sociologie, on envisage spécifiquement quelques implications et défis de la recherche sociale.

Mots-clé: réflexivité, sciences sociales, processus d'enseignement apprentissage, recherche. 


\section{Introducción}

La reflexividad repercute de forma teórica y práctica en las ciencias sociales contemporáneas. Teóricamente, conlleva una cierta "consciencia de crisis" sobre los fundamentos epistemológicos sobre los cuales se construyó y legitimó un conocimiento sobre la realidad social. En términos prácticos, genera la sospecha sobre las condiciones de producción y reproducción del oficio. Haciendo eco de esa preocupación por la reflexividad, propia de un gran giro epistemológico y político que sufren las ciencias sociales en las últimas tres décadas, pero también de todo un clima de grandes transformaciones para el ejercicio práctico de las disciplinas y los saberes sociales, este ensayo se propone realizar un ejercicio de reflexividad sobre los procesos de enseñanza y aprendizaje de la investigación en ciencias sociales.

La influencia de la obra de Pierre Bourdieu ha sido decisiva en la generación de esta preocupación, especialmente su propuesta de ejercer una constante "vigilancia epistemológica" sobre las condiciones histórico-sociales desde la que se produce investigación, así como de la posición que asumimos como maestros dentro de las lógicas y estructuras del campo académico y del contenido que adquieren nuestras prácticas académicas cuando son incorporadas y objetivadas dentro y fuera del salón de clases.

En nuestro medio, el tema de la reflexividad sobre los procesos de enseñanzaaprendizaje de las ciencias sociales locales es reciente. Intuitivamente se puede afirmar que la cuestión fue parte de un olvido rutinizado, al considerarse normal enseñar y aprender cualquier disciplina social sin discutir sobre cómo se estaban abordando en el aula de clases y en conexión con la cotidianidad los problemas sociales, los métodos y los enlaces con las teorías. Nuestros maestros crecieron académicamente e incluso forzaron el crecimiento de muchos, considerando que los pregrados en ciencias sociales, especialmente en sociología, eran escenarios para realizar exégesis de los clásicos. Algunos atrevidos y heréticos llegaron a realizar desde su propio oficio docente lecturas parciales de autores contemporáneos y poco canónicos; otros, a plantear problemas de investigación en los cursos; y en algunas ocasiones, a realizar ejercicios de campo con sus estudiantes 
o proponer análisis descriptivos en el aula sobre la base de algunas de sus investigaciones empíricas. En tales ambientes, muchos de nosotros -y hablo incluso de la generación de los treintañeros de la sociología- circulamos por el pregrado y llegamos al trabajo de grado con un mapa bastante amplio, pero descolocado y roto de la teoría social, así como un conocimiento incipiente de los métodos y las técnicas, con el desconcierto final de qué hacer en el trabajo de grado, qué problemas y preguntas formular, qué enfoques escoger, cuál método seguir o por cuáles técnicas optar. La urgencia de esta última fase provocaría en muchos el paroxismo de "aprender haciendo", no porque esto no fuera necesario y útil en todo caso, sino porque se nos presentaba en la última fase de la carrera, a las puertas de un mercado laboral que nos demandaba retos desconcertantes.

Ahora bien, en el mercado de trabajo local, se ha reconocido al sociólogo como un teórico del mundo social, con un dominio específico de técnicas y herramientas para traducir la complejidad, las aristas y los lenguajes de las realidades sociales. Sin embargo, ese reconocimiento es resultado más de lo que el sociólogo ha logrado hacer y posicionar desde la práctica especialmente en ciertas áreas y campos donde sus conocimientos y habilidades eran y aún siguen siendo requeridos: la consultoría, la elaboración de planes de desarrollo, el diseño de diagnósticos locales, la formulación y evaluación de políticas y programas sociales, el manejo de paquetes socioestadísticos. El prestigio del cual gozó en estas esferas laborales no estuvo acompañado previa y programáticamente de un ejercicio de reflexividad desde los programas de estudio de sociología del país, sobre la enseñanza de los métodos, las metodologías, las técnicas y la conexión de éstas con las teorías y los problemas sociológicos. No fue un problema para la academia sociológica y por tanto no lo debía ser para el sociólogo.

Este ensayo de alguna forma trata de situar y visibilizar esa ausencia de reflexividad sobre las condiciones de producción del conocimiento social, así como de las lógicas y contenidos de la enseñanza-aprendizaje de la investigación en ciencias sociales. Lo hace desde la sociología y desde el ejercicio práctico de la docencia universitaria. 
Dos ejes centrales articulan toda la discusión. El primero conduce a la reflexión sobre la emergencia de la reflexividad en la teoría social contemporánea y en la práctica del oficio, especialmente desde algunas propuestas teóricas contemporáneas. El segundo ubica al lector en relación con las implicaciones y retos de los procesos de enseñanza y aprendizaje de la investigación en ciencias sociales. Lo que se consigna aquí no es más que un ejercicio artesanal de sistematización de algunas intuiciones, discusiones de clase y reflexiones con colegas y amigos. Más que un texto acabado, el ensayo es una provocación a seguir discutiendo sobre el tema.

\section{La emergencia del problema de la reflexividad en la teoría y en el oficio}

Desde hace ya varias décadas asistimos a un proceso macro de transformación de las condiciones de producción y reproducción del conocimiento en las ciencias sociales. Esta transformación está operando en distintas dimensiones, no de manera homogénea pero sí de forma transversal y más o menos permanente, tanto en los supuestos epistemológicos, como en los alcances políticos y prácticos de la investigación social. Hay diferentes y suficientes razones que explican que dichas condiciones hayan cambiado y múltiples las interpretaciones de dicho proceso. Las causas de dicha transformación corresponden en esencia a una crisis, que comienza con la transformación del canon anglosajón de la ciencia social y la emergencia de dos paradigmas o giros: el cultural y el lingüístico.

De hecho, varios autores (Denzin, 1997; Marcus y Fisher, 2000; Vera y Jaramillo, 2007) sostienen que esta crisis se expresa, por lo menos, de tres formas: por un lado, es una crisis de representación que ha erosionado la noción clásica de sujeto-objeto y las formas convencionales de esta relación; por otro, es una crisis de legitimidad que cuestionó el estatuto "científico de lo social"y la emergencia de reflexiones sobre la representación de lo social en la escritura sociológica y antropológica; y por último, es una crisis de la práctica de las ciencias sociales, expresada en un debate epistemológico y político que coloca en cuestión el sujeto de conocimiento y la relación que él establece con los otros sujetos y con los contextos sociales en que se encuentran inmersos. 
La convergencia de esta triple erosión se manifiesta de forma radical en el estilo y contenido de la teoría social contemporánea y en el oficio del investigador social. En ambos casos, un eje central de articulación es la emergencia del problema de la reflexividad, dimensión que quiero destacar en este ensayo. En el primer caso, la reflexividad se asocia a una perspectiva teórica, interna a la propia ciencia social, sobre los riesgos, costos e incertidumbres producidos por el proyecto moderno eurocentrista. En el segundo caso, se le conecta a un ejercicio autocrítico sobre el modus operandi del antropólogo y sociólogo, que los conduce a ambos a desentrañar las contradicciones internas del campo de producción cultural y teórica en que se encuentran. Examinemos rápidamente estas dos vías.

\section{La reflexividad teórica}

La reflexividad teórica conlleva la idea que la teoría social, más que un dispositivo de legislación sobre la realidad, es una caja de herramientas de la cual dispone críticamente el intelectual para traducir y afrontar, desde la praxis, las asimetrías e impactos de una modernidad marcada por procesos de individualización reflexiva y condiciones estructurales que constriñen a los individuos. Esta reflexividad da cuenta de cómo las personas tienen que evaluar los riesgos de sus propias decisiones y afrontarlos biográficamente, pese a sus costos. El esbozo sustancial de esta reflexividad teórica se encuentra preliminarmente en la teoría crítica de la sociedad, especialmente la desarrollada por Horkheimer y Adorno (1994), a mediados del siglo XX.

En estos teóricos, la reflexividad emerge como un presupuesto epistemológico y político de una teoría crítica que examina con sospecha el fundamento mismo de la tradición moderna, es decir, esa racionalidad dura e instrumental que denota una confianza absoluta en un mundo ordenado, diseñado y administrado. La reflexividad está entonces en función del develamiento de la instrumentalización del ideario de la llustración, de aquel clásico "sapere aude" (atreverse a pensar por sí mismos) que ha devenido con el tiempo en un pensamiento sometido a las nuevas formas de control social, político y tecnológico que emergen con el avance de las sociedades industriales y las industrias culturales de masas. 
La visión de una teoría social reflexiva de sus propios fundamentos llegará hasta nuestros días de la impronta de varios autores. Aparece en Popper (1961). Aquí, este filósofo critica fuertemente las tendencias de pensamiento que reducen la realidad a un epifenómeno de estructuras históricas objetivas, las cuales determinan totalmente la acción de los sujetos. Al plantear su popular tesis que la ciencia avanza refutando ideas, pero bajo un ejercicio de validación intersubjetiva, este filósofo hace frente al historicismo impugnando sus principales bases, pero también a cualquier clase de determinismo, otorgándole unos cimientos fuertes a una idea potente hasta el día de hoy en la ciencia social, que es la del conocimiento colaborativo y la validación dialógica del saber.

El asunto de la reflexividad teórica destaca también en Bauman (2005), quien sostiene que la modernidad entra en una fase de reflexividad de sus fundamentos, en una especie de fase de "inventario de sus ganancias y pérdidas" (p. 358). En ese sentido, es consciente que una nueva teoría social exige del sociólogo ser un traductor de los problemas de su tiempo y no simplemente un legislador que produce recetas discursivas sobre la realidad (Bauman, 1997). Este supuesto asume que la teoría tiene que ver también con la puesta en escena del sentido de los problemas específicos de una sociedad en un espacio-tiempo y no sólo con una explicación causalista de los fenómenos sociales.

Este tema es evidente también en la obra de Beck (1998), quien asume que frente a una teoría de sociedad concebida como totalidad y encarnada en las grandes metanarrativas del estructuralismo, el marxismo, el funcionalismo y el positivismo (inmersas en las categorías explicativas de la sociedad, por ejemplo: clase social, estructura, Estado e instituciones) comienzan a emerger categorías más flexibles y dúctiles de análisis de la realidad social, así como teorías críticas a los paradigmas dominantes. Tal es el caso de la teoría de la elección racional, de la agencia, de los discursos hermenéuticos y de las tendencias post marxistas y post positivistas. Para Beck (1998), la marca más notoria de ese tipo de reflexividad es "la disolución del monopolio de la verdad de la ciencia" (p. 217). 
Finalmente, es posible rastrear el impacto de la reflexividad en la teoría social a través de la obra de Giddens (2001), la cual la liga con un ejercicio de doble hermenéutica. Desde esta óptica los objetos sociales no son algo pre-dado o datos desnudos sino "objetos que están constituido o son construidos por quehaceres activos de los sujetos" (p. 192). Esta doble hermenéutica recuerda las imbricaciones complejas que operan entre el mundo social y la ciencia social, y viceversa. Las ciencias sociales son deudoras, en todo momento, de las prácticas discursivas que ocurren en la vida social. Pero, al mismo tiempo, el conocimiento que ellas producen es retomado por los agentes sociales en forma de conocimiento experto. Así, el mundo social ocurre en una especie de"intersección de dos marcos de sentido:... el mundo social constituido por unos actores legos y unos metalenguajes inventados por los especialistas en ciencia social; [de tal forma que siempre] hay un constante deslizamiento entre un marco y otro" (Giddens, 1998, p. 396).

\section{La reflexividad en la práctica}

Si la reflexividad teórica conduce la teoría social a evaluarse internamente en sus fundamentos, la reflexividad práctica produce que etnógrafos, antropólogos y sociólogos visibilicen y problematicen relaciones antes naturalizadas y objetivadas, entre autor y poder, texto e interpretación, subjetividad y objetividad. Conduce igualmente a que estos se pregunten por asuntos tan importantes para su oficio como: ¿cuál es la posición social del investigador en el campo de la interpretación?, ¿cuáles son las relaciones de poder en las que se mueve y se encuentra inmerso?, ¿cuál es el horizonte de representación desde el que habla el investigador social, de la cultura y de la sociedad?, ¿cómo se están interviniendo realidades culturales y políticas? y ¿qué postura o distancia asumir frente a los mecanismos y dispositivos de dominación social?

Es Bourdieu uno de los pensadores que mejor condensa este ejercicio en su oficio como investigador. Desde su óptica, la reflexividad pasa no sólo por la objetivación de la teoría, sino por la práctica misma de la investigación desde donde se produce esta teoría. Sin embargo, no basta que el ejercicio de reflexividad se concentre en el cuestionamiento del 
quehacer del investigador, es necesario que repercuta en las prácticas más institucionalizadas y ancladas dentro del campo científico, es decir, que logre ser reformadora de las condiciones y disposiciones estructurales del campo, con la condición de que, dentro del mismo, afecte "al conjunto de agentes comprometidos... con el imperativo de la reflexividad, [así como] al sistema de disposiciones y posiciones dentro del campo" (2003, p.159).

En la medida que Bourdieu (2003) piensa la reflexividad como "el trabajo mediante el cual la ciencia social, [se toma] a sí misma como objeto, y se sirve de sus propias armas para entenderse y controlarse" (pp.154-155), destaca la importancia de ejercer una constante vigilancia epistemológica sobre los recursos teóricos y metodológicos utilizados en la práctica por el sociólogo o por el antropólogo. Quizá aquí lo más importante es su llamado a "convertir la reflexividad en una disposición constitutiva de su habitus científico, es decir, en una reflexividad refleja, capaz de actuar no ex post, sobre el opus operatum, sino a priori, sobre el modus operandi" (Bourdieu, 2003, p. 155). Esa reflexividad que cuestiona el modo de producir conocimiento y aplicar el método permite a sociólogos y antropólogos deconstruir sus prácticas y los modos de operación como sujetos dentro de un campo de producción científica, cuya acción y percepción está atravesada siempre por prácticas institucionalizadas y por el habitus del investigador.

Desde la producción antropológica contemporánea ${ }^{3}$ también se encuentran referencias explícitas a la reflexividad ligada al oficio del etnógrafo, específicamente desde la llamada etnografía experimental (Clifford y Marcus, 1986; Clifford, 1991; Marcus y Fisher, 2000; Rabinow, 1991; Taussig, 1995) ${ }^{4}$. En todos ellos (explícita o implícitamente) el problema clave es el de la reflexividad como un cuestionamiento crítico a la escritura y al intento

3 La discusión sobre la incorporación de la reflexividad en la antropología contemporánea no se agota en las referencias dadas aquí, en este ensayo. Se recomienda en este sentido, acudir a Denzin (1997), que identifica cinco estilos de reflexividad asociados con la etnografía: subjetivista, metodológica, intertextual, feminista o standpoint theory y queer. Si bien, esta clasificación no deja de ser arbitraria, resulta muy útil para dar cuenta de las múltiples dimensiones del asunto en la antropología contemporánea. También se recomienda el texto de Guber (2001), que aborda las distintas vías por las cuales entra la reflexividad en las discusiones antropológicas.

4 En Clifford Geertz y su texto El antropólogo como autor (1998), se pueden documentar los inicios de esta preocupación, aunque la antropología postmoderna intenta separarse críticamente de este autor. Cf. Cairo y Jaramillo (2008). 
por promover, a partir de ella, unas nuevas formas de representación etnográfica. La reflexividad aparece entonces como auto-reflexividad textual, sobre la manera como se escribe y para quien se escribe (Marcus y Cushman, 1991, p.172). Pero también la reflexividad emerge como ejercicio de descentramiento y cuestionamiento del lugar y el contexto desde donde se escribe. Taussig $(1995 ; 2005)$ representa uno de los escritores más prolíficos en este sentido. Su trabajo etnográfico realza su propia experiencia como antropólogo en zonas de conflicto, donde las categorías y los relatos por él producidos muestran las múltiples caras del terror, el papel del antropólogo frente a las dinámicas de violencia y la naturalización que se hace de ella en la sociedad colombiana.

Una de las principales características de esta reflexividad práctica es la incorporación e integración, dentro de las prácticas de investigación, de una preocupación explícita por las diversas maneras como se construyen las interpretaciones objetivas sobre el mundo social. En este sentido, la reflexión se extiende hacia el sentido y alcances de la representación textual y qué tanto repercute ella en la objetivación, naturalización y ocultamiento de los sujetos dentro de la investigación y la producción literaria. Precisamente, uno de los aportes de esta posición es el reto que le plantea a los presupuestos más rígidos del oficio del sociólogo y el antropólogo, particularmente a la hora de definir desde dónde se investiga y se escribe, desde dónde se construyen explicaciones e interpretaciones del otro. Exige, por tanto, la búsqueda de salidas de representación alternativas que subviertan la relación dominante y canónica entre autor y poder, sujeto y objeto e interpretación intersubjetiva e interpretación científica de corte formalista.

Algunas de las pistas más disruptoras de este giro teórico y práctico en las ciencias sociales sirven de pretexto para proponer a continuación un ejercicio de reflexividad desde la práctica docente local, sobre los procesos de enseñanza-aprendizaje de la investigación social. 


\section{Un ejercicio de reflexividad desde el oficio docente sobre los procesos de enseñanza-aprendizaje de la investigación en ciencias sociales}

Los procesos de enseñanza-aprendizaje de la investigación en ciencias sociales pasan definitivamente hoy por reivindicar la idea de que educamos en una disciplina, pero además en un oficio. Es decir, el sociólogo que formamos no debe ser exclusiva y llanamente un teorizador fuera de toda realidad local, pero tampoco un empírico a secas, que a partir de un capital de conceptos o de un arsenal de técnicas y paquetes estadísticos trata de descifrar como dé lugar el sentido del mundo que le rodea (Wainerman y Sautu, 2001). Su condición debe ser la de un practicante de un oficio y una artesanía intelectual en las cuales coexisten teoría y práctica. Pero avanzar en la recuperación del oficio del sociólogo implica tomar en cuenta que los problemas del mundo contemporáneo exigen, además de evitar el divorcio entre teoría, método y metodologías, pensar cómo hemos entendido la enseñanza de la teoría y los métodos sociológicos, cómo estos responden a los desafíos de nuestra época y de nuestros contextos nacionales y locales. La gran dificultad es que hemos sido formados en esa esquizofrenia de separar método y teoría, y lo estamos reproduciendo perversamente con nuestros estudiantes, leyendo a los autores clásicos y contemporáneos en unos cursos y enseñando metodologías en otros, lo que es normal en nuestros currículos, pero no estableciendo desde la organización curricular, los puentes y las conexiones debidas.

La reconciliación entre teoría y método pasa también por superar las diferencias patológicas entre la investigación cualitativa y cuantitativa. Como parte del ejercicio de docencia, sigue teniendo sentido reforzar la tesis de que las diferencias entre estas dos son sólo de estilo y no de naturaleza. Así, para algunos, éste sea un debate estéril y superado en las ciencias sociales contemporáneas, es crucial seguir trabajando en ello dentro de las aulas de clase. Es decir, hay que insistir en que si bien epistemológica y técnicamente ambas proceden distintamente, los dos tipos de investigación funcionan e interactúan continuamente bajo una misma lógica inferencial (King, Keohane y Verba, 2000) con pretensiones de validez sobre lo social (Newman 
y Benz, 1998). Lo anterior nos debe conducir entonces a asumir que, para entender la lógica de la investigación sociológica, si bien la investigación cualitativa pretende encontrar el significado cultural de una situación y la interpretación del sentido de lo que dicen y hacen los sujetos en la realidad social, y la investigación cuantitativa pretende buscar la explicación de esa realidad mediante la comprobación de hipótesis, es necesario que los estudiantes reconozcan que el control estadístico de los sujetos de estudio y la generalización de las explicaciones, ambos tipos, no pueden desconocer que su principal objetivo es "[inferir descripciones o explicaciones] a partir de una información empírica que se tiene sobre el mundo social" (King, Keohane y Verba, 2000, p. 18).

Enseñar el valor de la inferencia es enfatizar que ella implica unos procedimientos y unas reglas que permiten garantizar la validez interna y externa, así como la confiabilidad de los datos y los procedimientos; aunque también es necesario mostrar que ella no es sólo acumulación de hechos, sumatoria de observaciones o la simple expedición de cálculos estadísticos, ejercicios muy comunes en toda investigación social. Se entiende la inferencia más como un proceso de "impregnación conceptual” de la realidad; es insistir en su valor en tanto operación de revelación de lo que la realidad no dice a primera vista, pero que es deber del sociólogo dar a conocer a través de una artesanía analítica más elaborada, sea ésta de carácter descriptivo, explicativo o predictivo. En este sentido, hay que afianzar en los procesos formativos la tesis de que la inferencia es un procedimiento lógico y teórico muy útil, mediante el cual hacemos "hablar a los hechos", claro está sin exceder lo que ellos son y dicen, pero sí llevando hasta un límite permitido la revelación de nuevos sentidos o nuevos efectos causales de aquellos que observamos inicialmente. Aquí no estaría de más recordar las palabras del sociólogo francés Lahire (2006) cuando afirma "que el investigador social debería tener cuidado con no'proyectar' en la cabeza de aquellos cuyas prácticas estudia, la relación que él mismo mantiene, en su calidad de sujeto cognoscente, con el objeto de conocimiento" (p. 52).

De otra parte, si bien el ejercicio reflexivo ha de llevarnos a declarar como insostenible el gap entre los enfoques cualitativo y cuantitativo, también 
debe permitir mostrar las razones de insostenibilidad de dicha separación. De ahí la importancia de explicar que, si bien las rupturas tuvieron origen en visiones paradigmáticas de la realidad social, producto de raíces filosóficas (por ejemplo, la una de corte naturalista-fenomenológico-constructivista y la otra de raigambre empirista-positivista-objetivista), incluso con hondas repercusiones sobre formaciones metodológicas monolíticas que algunos de nuestros maestros o nosotros mismos tuvimos en nuestras licenciaturas o pregrados, no tienen porqué seguir vigentes hoy. Al menos dos razones podrían esgrimirse para justificar este punto de vista. En primer lugar, el que exista una misma lógica inferencial refleja, de hecho que la separación entre estos dos tipos es una falsa dicotomía. Es decir, mientras más integradas estén en una investigación las posturas y las técnicas cualitativas y cuantitativas, más validez tiene un estudio y las inferencias que éste produce. En segundo lugar, la investigación de hoy supone la aceptación de un fundamento y una disposición holística y compleja en la manera de hacer ciencia y en los presupuestos epistemológicos de lo cualitativo y lo cuantitativo. Este fundamento considera que ningún tipo de investigación es más valiosa que otra; o debe tener el predominio sobre lo real o debe disociar esquizoidemente al científico social. En este sentido, cada enfoque contribuye a nuestro problema de investigación sobre el principio de la retroalimentación constante de información que proviene de lado y lado. Este principio deriva también de la idea popperiana de la validación intersubjetiva. De allí que todo conocimiento deba estar abierto a la crítica de la comunidad de pares. Precisamente está en nuestro ejercicio docente hacer visible que los científicos avanzan contemplando y, en ocasiones, rompiendo, pero en todo caso dialogando con las observaciones y hallazgos de otros, y ello implica tomar en cuenta el gran acervo de ideas y experiencias provenientes y acumuladas en la comunidad científica.

En el proceso de enseñanza-aprendizaje de la investigación social es necesario enfatizar que, frente a la comprensión del mundo, el cientista social hace uso de unas estructuras lógicas para preguntar y convertir problemas sociales en problemas sociológicos; que en su quehacer intelectual y práctico se vale de unas formas y estrategias de organización de los datos que construye sociológicamente y que en su camino los va insertando, descolgando y 
tejiendo dentro de unos enfoques teóricos clásicos y contemporáneos. En este sentido, habría que ayudarles a reconocer que cuando el sociólogo utiliza teorías, sean éstas clásicas y contemporáneas, ellas le deben servir en esencia, como dice Alexander (1990), para "estructurar la realidad social", no a partir de las creencias de lo que para los sociólogos clásicos o contemporáneos era o representaba el mundo, sino a partir de lo que ellos identificaron en su dimensión sociológica dentro de su entorno, es decir, como fabricaron su artesanía de pensamiento, como utilizaron en su producción literaria el método sociológico y como lograron traducir un caótico escenario de problemas en una gran arquitectura conceptual y categorial. En ese sentido, soy del parecer que la enseñanza y el aprendizaje de la investigación deberían obligarnos con nuestros estudiantes a la recuperación y lectura de estudios monográficos globales y locales, importantes para la sociología y para otras disciplinas. A través de esa lectura, debería recuperarse el uso particular del método y las técnicas utilizadas por dichos autores para recabar datos. Resulta más valioso para el oficio que tienen que ejercer nuestros estudiantes mostrar cómo se utilizaron los documentos personales en un estudio como el de Howard Becker sobre los Outsiders o evidenciar cómo Foucault hizo acopio e interpretó los documentos históricos para reconstruir la memoria del parricida Pierre Rivière.

De lo anterior se desprende también un principio crucial para la enseñanza y el aprendizaje de la investigación: la teoría no está ni al principio ni al final de un proceso de indagación. La teoría se encuentra presente durante todo el proceso. Ella supone un ir y venir entre los datos, la pregunta de investigación, la bibliografía consultada, las hipótesis generadas. Además, esa forma de pensar la teoría implica el reconocimiento de una incertidumbre permanente frente a ella. Es decir, toda teoría sobre lo social es perfectible y falseable en cualquier circunstancia. Pero también conlleva la idea de la teoría en tanto caja de herramientas permanente para el investigador. Con los estudiantes es preciso reconocer que cuando voy a terreno no voy desprovisto de ella, a pesar de que pueda ser del parecer que los datos recogidos también me permiten que ella emerja (como sería la posición de los defensores más radicales de la Grounded Theory); además, es necesario enfatizar que cuando regreso de terreno y estoy analizando los datos, vuelvo una y otra vez sobre 
ella; también cada que codifico los datos aparece, al igual que al momento de elaborar la pregunta de investigación o de enfrentar qué métodos utilizar.

El ejercicio reflexivo sobre el oficio debería llevar también al docente a colocar de relieve las especificidades, los rasgos y las huellas del mundo social que el sociólogo construye, mostrando, sin embargo, que, aunque el sociólogo utiliza un método diferente para descifrar el mundo, siempre es complementario y está enlazado con el de los antropólogos o historiadores. Es decir, reconocer que desde ópticas y posiciones distintas en el mundo social, y aunque se valga de metodologías diversas, en muchas ocasiones lo que hace y dice el sociólogo se cruza con lo que dicen y hacen los historiadores y antropólogos. Pero es importante hacer notar que el método o los métodos no son simplemente "recetas de cocina científica" o "rituales de procedimiento", sino que son formas singulares de abordaje, de captura, de lectura e interpretación del dato social; que, además, dado el enfoque teórico con el cual se pretende leer la realidad, también así dependerán las metodologías utilizadas y, dentro de ellas, las técnicas más apropiadas para recabar el dato (Bourdieu, Chamboredon y Passeron, 2003). En suma, el docente debe insistir en la tesis de que sea cual sea la metodología que el investigador utilice, así como el enfoque teórico que privilegie, el sociólogo mira el mundo siempre bajo la lupa de un marco de lectura y abordaje.

La enseñanza y el aprendizaje de la investigación en sociología pasa también por reconocer que no son suficientes los cursos sobre metodología ofertados a lo largo de la carrera para formar en el oficio. La mayoría de nosotros aprendimos en su momento al lado de la artesanía investigativa de un buen maestro y ello deberíamos replicarlo permanentemente con nuestros estudiantes. Privilegiar la vinculación de ellos a nuestros proyectos es de vital importancia para el desarrollo de la carrera. El asunto es que éste es un proceso lento y sinuoso y demanda insistir que la investigación es una disposición que comienza y se pule en los cinco años del pregrado, se labra con el diálogo sostenido con ellos a partir de sus inquietudes y se perfecciona más allá del pregrado. Es importante, en esa transmisión del oficio, trabajar en la recolección del dato, en la forma como nosotros lo hemos hecho y cómo lo podrían hacer ellos. Evidenciar que el oficio del sociólogo requiere 
una rutina que pasa por la fabricación de fichas bibliográficas, aprender a citar bien, revisar bases de datos en la biblioteca, hurgar en documentos oficiales, rastrear archivos, capturar datos, procesar en algunos programas socioestadísticos, analizar constantemente información proveniente de bases electrónicas y estadísticas, etc.; mostrar que en el oficio del investigador no debemos olvidar ser flexibles y plásticos al momento de recabar los datos (lo que no implica renunciar al rigor); insistir en que investigar es un arte, donde no hay reglas fijas, sólo pautas.

Insistir en la artesanía de la investigación es cultivar en nuestros estudiantes la agudeza para detectar la relación dinámica y las tensiones entre lo microscópico y lo macroscópico. Nuestra labor debería estar al servicio de enseñar a densificar ciertas situaciones que observamos como familiares, pero que escudriñándolas nos revelan, por ejemplo, escenarios novedosos; pero también a situar esas pequeñas pesquisas en preguntas y contextos más macro, más globales y menos situacionales. Resumiría esto diciendo que es un proceso de ida y vuelta entre dos artesanías de investigación célebres, la de Marx y la de Simmel (y también la de Goffman). El primero nos enseñó el valor de la comprensión de los fenómenos sociales mediante su ubicación en estructuras de largo alcance, tanto espacial como temporalmente, sin aislar y volver ahistóricas las explicaciones o las interpretaciones. Los otros dos nos legaron la necesidad de la finura en la observación, crucial para detectar en los roles que los individuos desempeñan en la sociedad, las formas sutiles y transparentes, pero también en las encubiertas o descaradas de simulación. No obstante, la ida y vuelta entre estas dos artesanías debe llevarnos a enfatizar con nuestros estudiantes en los riesgos de situarnos con exclusividad en una u otra orilla. Una visión macro de los fenómenos puede conducirnos al diletantismo enciclopédico y una visión micro, al "impresionismo sociológico". Para no ser presa ni de lo uno, ni de lo otro, ni de las estructuras, ni de las escenas y situaciones será indispensable mantener la vigilancia epistemológica.

Ahora bien, la reflexividad se debe orientar también al cuestionamiento radical de la práctica de la escritura para el sociólogo. Dentro del oficio es crucial preguntar ¿qué hacemos con los datos?, ¿cómo escribimos?, ¿cómo 
ordenamos?, ¿cómo se insertan y dialogan los datos recogidos con nuestro estilo de escritura? Esto pasa por subvertir y deconstruir las formas clásicas de comunicación. Durante mucho tiempo los sociólogos hemos privilegiado la descripción de datos estadísticos y el ensayo teórico como la escritura científica por excelencia. Pero es necesario mirar otras opciones, como presentar una historia de vida, un relato oral, un fotomontaje, un sonoviso, un documental. Un buen ejemplo de cómo pueden subvertirse estas formas lo encontramos en algunos autores, por ejemplo, en la obra de Bourdieu (1999), en la que, al transcribir y analizar los relatos de inmigrantes, artesanos, maestros obreros, cuestionan internamente las implicaciones que tendría que escribir y teorizar sobre otros. Otra forma de escritura que subvierte esos cánones clásicos se evidencia en el trabajo de Wacquant (2006), en el que, además de incursionar etnográficamente en los clubes de entrenamiento boxístico en un gueto negro de Chicago, produce una escritura que coloca en escena una multiplicidad de géneros y estilos narrativos e interpretativos.

En las carreras de sociología debe, por tanto, existir un espacio de taller permanente para desarrollar la artesanía y la creatividad, tanto en la recolección de datos, como en la escritura clásica y en las nuevas escrituras. Un espacio en el que se puedan aprender a realizar buenas observaciones, buenas entrevistas en profundidad, notas de campo, levantamiento de memoria visual de nuestras ciudades, pero también donde se enseñe a escribir y subvertir el canon, donde se enseñe a escribir menos como legisladores del mundo y más como interpretes frescos de realidades difusas.

Finalmente, un ejercicio de más largo plazo orientado a pensar la enseñanza y el aprendizaje de la investigación nos debería poner en sintonía con nuestros estudiantes sobre cómo hemos realizado investigación sociológica en el país y utilizado métodos y técnicas diversas. Sería importante reconstruir la génesis social e histórica de la producción sociológica en el país, no ya para evidenciar cuál ha sido la historia del pensamiento sociológico en Colombia, sino cómo hemos investigado, qué hemos investigado, cómo se ha desarrollado el oficio de sociólogos en Colombia, cómo hemos escrito y desde qué lugares sociales, perspectivas teóricas y estilos literarios en estos 50 años de sociología institucional en el país. 


\section{Reflexiones finales}

A lo largo de este texto se ha sostenido que la reflexividad es una dimensión inherente tanto a la crisis de fundamentos epistemológicos de la ciencia, como al modus operandi del investigador social. En la reflexión sobre la primera dimensión destacamos el ejercicio interno de deconstrucción de los alcances y límites de la teoría social. Respecto a la segunda dimensión hicimos hincapié en la importancia que tiene la reflexividad como una actitud y una disposición que conducen al investigador a situarse en una lógica interna del campo de su producción cultural y teórica, con enormes contradicciones. A través de estas dos dimensiones sugerimos asumir la reflexividad como una estrategia epistemológica que le permita al investigador descentrarse de su logos y de aquellos presupuestos doxológicos impuestos por la teoría social y por las formas ortodoxas de hacer ciencia, incluso las que se trasplantan y aplican localmente. En este sentido, es posible considerar y defender que la práctica y el ejercicio reflexivo constituyen un paso adelante del pensamiento social por promover un conocimiento emancipador para el científico y para los otros.

Se puede inferir a partir del ejercicio reflexivo realizado sobre los procesos de enseñanza-aprendizaje de la investigación que la reflexividad es un proceso posicional mediante el cual el investigador novel reconoce que está histórica y geográficamente situado en su oficio, que ocupa un espacio social determinado y determinante, afectado por los escenarios de producción, de recolección y de interpretación de la información. Educar sobre este posicionamiento es hacer consciente que todo ejercicio investigativo es una especie de ida y vuelta permanente entre el sujeto cognoscente, otros sujetos y los contextos sociales observados. Este posicionamiento va acompañado a su vez de una disposición de vigilancia y control sobre los datos que se recogen, las condiciones de recolección de estos datos y los marcos teóricos con los cuales estos datos dialogan. La disposición implica también una flexibilidad constante sobre los mecanismos textuales y comunicativos en los cuales se procura hacer públicos los resultados de investigación. El reto adicional sería educar en el reconocimiento de las problemáticas de la sociedad que efectúan las ciencias sociales, pero en lenguajes más diversos y novedosos, que trasciendan los estilos monográficos sociológicos clásicos. 


\section{Referencias}

Adorno, T. y Horkheimer, M. (1994). Dialéctica de la llustración. Fragmentos filosóficos. Madrid, España: Trotta.

Alexander, J. (1990). Las teorías sociológicas desde la Segunda Guerra Mundial. Barcelona, España: Gedisa.

Bauman, Z. (1997). Intérpretes y legisladores. Sobre la modernidad, la postmodernidad y los intelectuales. Buenos Aires, Argentina: Universidad Nacional de Quilmes.

Bauman, Z. (2005). Modernidad y ambivalencia. Barcelona, España: Anthropos.

Beck, U. (1998). La sociedad del riesgo. Hacia una nueva modernidad. Barcelona, España: Paidós.

Bourdieu, P. (Ed.). (1999). La miseria del mundo. Madrid, España: Akal.

Bourdieu, P. (2003). El oficio del científico: ciencia de la ciencia y reflexividad. Barcelona, España: Anagrama.

Bourdieu, P., Chamboredon, J. C. y Passeron, J. C. (2003). El oficio del sociólogo. Presupuestos epistemológicos. México: Siglo XXI.

Cairo, C. L. del y Jaramillo, J. (2008). Clifford Geertz y el Ensamble de un Proyecto Antropológico Crítico. Revista Tabula Rasa, (8), 15-41.

Clifford, J. (1991). Sobre la Autoridad Etnográfica En J. Clifford y C. Geertz (Eds.), El surgimiento de la antropología posmoderna (pp. 141-170). México: Gedisa.

Clifford, J. y Marcus, G. (1986). Writing culture: the poetics and politics of ethnography. Berkeley, California, EE. UU.: University of California Press.

Denzin, N. (1997). Interpretative ethnography. Ethnographic practices for 21st century. Thousand Oaks; California, EE. UU.: Sage. 
Geertz, C. (1989). El antropólogo como autor. Barcelona, España: Paidós.

Giddens, A. (1998). La constitución de la sociedad. Buenos Aires, Argentina. Amorrortu.

Giddens, A. (2001). Las nuevas reglas del método sociológico. Buenos Aires, Argentina: Amorrortu.

Guber, R. (2001). La etnografía: método, campo y reflexividad. Bogotá, Colombia: Norma.

King, G., Keohane, R. y Verba, S. (2000). El diseño de la investigación social. La inferencia científica en los estudios cualitativos. Madrid, España: Alianza.

Lahire, B. (2006). El espíritu sociológico. Buenos Aires, Argentina: Manantial.

Marcus, G. y Cushman, D. (1991). Las Etnografías como Textos. En C. Reynoso (Ed.), El surgimiento de la antropología posmoderna. Barcelona, España: Gedisa.

Marcus, G. y Fischer, M. (2000). La antropología como crítica cultural: un momento experimental en las ciencias humanas. Buenos Aires, Argentina: Amorrortu.

Newman, I. and Benz, C. R. (1998). Qualitative-quantitative: exploring the interactive continuum. Illinois, EE. UU,: Southern Illinois University Press.

Popper, K. (1961). La miseria del historicismo. Madrid, España: Taurus

Rabinow, P. (1991). Las Representaciones son Hechos Sociales: Modernidad y Postmodernidad en la Antropología. En J. Clifford y G. Marcus (Eds.), Retóricas de la antropología (pp. 321-356). Madrid, España: Júcar.

Taussig, M. (1995). El Terror como Lugar Común: la Teoría de Walter Benjamín de la Historia como Estado de Sitio. En M. Taussig, Un gigante en convulsiones: el mundo humano como sistema nervioso en emergencia permanente (pp. 25-55). Barcelona, España: Paidós. 
Taussig, M. (2005). Law in a lawless land: diary of a limpieza in Colombia. Chicago, EE. UU.: University of Chicago Press.

Vera, J. P. y Jaramillo, J. (2007). Teoría Social, Métodos Cualitativos y Etnografía: el Problema de la Representación y Reflexividad en las Ciencias Sociales. Universitas Humanística, (64), 237-255.

Wacquant, L. (2006). Entre las cuerdas. Cuadernos de un aprendiz de boxeador. México: Siglo XXI.

Wainerman, C. y Sautu, R. (2001). La trastienda de la investigación. Buenos Aires, Argentina: Lumiere. 